\title{
Association of dementia with death after ischemic stroke: A two-year prospective study
}

\author{
CHANG-YUE GAO*, YAN LIAN* , MENG ZHANG, LI-LI ZHANG, CHUAN-QING FANG, \\ JUAN DENG, JING LI, ZHI-QIANG XU, HUA-DONG ZHOU and YAN-JIANG WANG \\ Department of Neurology and Center for Clinical Neuroscience, Daping Hospital, \\ The Third Military Medical University, Chongqing 400042, P.R. China
}

Received January 25, 2016; Accepted July 22, 2016

DOI: $10.3892 /$ etm.2016.3538

\begin{abstract}
The association between dementia and the risk of death after ischemic stroke was investigated. Neurological, neuropsychological and functional assessments were evaluated in 619 patients with acute ischemic stroke. Dementia was diagnosed at admission and at three months after stroke onset. The patients were scheduled for a two-year follow-up after the index stroke. The Kaplan-Meier survival and Cox proportional hazards regression analyses were used to estimate the cumulative proportion of survival, and the association between dementia and risk of death after stroke. In total, 146 patients $(23.6 \%)$ were diagnosed with dementia after stroke. The cumulative proportion of surviving cases was $49.3 \%$ in patients with dementia after a median follow-up of $21.2 \pm 5.6$ months, and $92.5 \%$ in patients without dementia. Multivariate analysis revealed that dementia (HR, 7.21; 95\% CI, 3.85-13.49) was associated with death, independent of age, atrial fibrillation, previous stroke and NIH stroke scale. In conclusion, the mortality rate is increased in stroke patients with dementia. Dementia is an important risk factor for death after stroke, independent of age, atrial fibrillation, previous stroke, and the severity of the stroke.
\end{abstract}

\section{Introduction}

Epidemiological studies have consistently demonstrated that there is a high incidence rate of stroke and mortality $(11,663 / 100,000$ per year) in China (1). Poor outcomes after stroke have been reported in numerous countries

Correspondence to: Dr Yan-Jiang Wang or Dr Hua-Dong Zhou, Department of Neurology and Center for Clinical Neuroscience, Daping Hospital, The Third Military Medical University, 10 Changjiang Branch Road, Chongqing 400042, P.R. China

E-mail: yanjiang_wang@tmmu.edu.cn

E-mail: gaocy128@yahoo.com.cn

*Contributed equally

Key words: stroke, mortality, dementia worldwide (2-5). The risk factors of death after stroke include age, stroke severity, history, previous stroke and atrial fibrillation. Previous studies have focused on the association between death after stroke and the decline of cognitive function or dementia caused by stroke (6-8). The results suggested that dementia is a potentially important factor influencing survival after stroke (7,9-12).

With a population of 1.3 billion in China, the prevalence of patients with ischemic stroke is extremely high (1). Owing to racial differences and economic lifestyle, the mortality rate and its risk factors in Chinese patients after ischemic stroke may differ from that in western countries (13). At present, few studies have focused on the relationship between dementia and survival after stroke in China.

In the present study, we studied a large cohort of patients in Chongqing, China with acute ischemic stroke, to investigate the association of mortality with dementia post-stroke.

\section{Subjects and methods}

Subjects. From January 2005 to July 2008, patients with ischemic stroke who were admitted to Daping Hospital (Chongqing, China) were registered. Eligibility requirements included: i) acute onset of ischemic stroke within $48 \mathrm{~h}$; and ii) aged $\geq 55$ years. The diagnosis of ischemic stroke was confirmed when there were focal signs of cerebral dysfunction of acute onset lasting for $>24 \mathrm{~h}$, brain CT scan or MRI.

In total, 727 patients were admitted during the study period, and 95 declined to participate. Thus, 619 patients were enrolled into the present study.

Clinical assessment. During admission, the patients underwent structured demographic data, medical history, neurological and head imaging examinations. The data collected were: age, gender, educational level $(<6$ or $\geq 6$ years), cigarette smoking (current, past and non-smoking) and alcohol intake (daily, weekly, monthly and non-alcohol intake), heart diseases (myocardial infarction, atrial fibrillation, and heart failure, diagnosed and treated previously or during admission), hypertension (previously diagnosed and treated or systolic pressure $>160 \mathrm{mmHg}$ and/or diastolic pressure $>90 \mathrm{mmHg}$ persistently observed during admission after the acute phase), diabetes mellitus (previously diagnosed and 
treated or fasting glucose $>7 \mathrm{mmol} / \mathrm{l}$ in two blood samples after the acute phase), stroke severity (NIH stroke scale), neurological sign, and stroke features (location, type of lesion, and stroke mechanism).

Neuropsychological evaluation. During admission, the dementia before index stroke was assessed by inquiring close relatives of the patients using a Chinese version of the Informant Questionnaire on Cognitive Decline in the Elderly (IQCODE), previously validated in the Chinese population (14). Functional status prior to stroke was assessed with the activity of daily living (ADL) (15).

At three months after the index stroke, the subjects were administered with a battery of neuropsychological tests developed for use in epidemiologic studies of dementia $(16,17)$. This neuropsychological battery of tests included: the Chinese Mini-Mental State Examination (CMMS) (18), ADL (19,20), instrumental ADL (15), Pfeiffer's Outpatient Disability Questionnaire (POD) (21), the Fuld Object-Memory Evaluation (FOM) (22), rapid verbal retrieval (RVR) (23), revised Wechsler Adult Intelligence Scale (DS and BD subtests) (24), and the Hamilton Rating Scale for Depression. The normative data for these tests were previously established in a control group of healthy elderly volunteers living in the same urban area and with the same age, gender distribution, and cultural background (16). The score $\leq 1 \mathrm{SD}$ of normative value was judged as unnormative.

The diagnosis of dementia was performed by a group of senior neurologists and psychiatrists based on criteria modified from the Diagnostic and Statistical Manual of Mental Disorders, 4th edition (DSM-IV) (25).

Statistical analyses. Participants who were lost or declined for follow-up were considered as censored data. As the onset time of dementia was not exactly observed, we defined the time to an event as the time of a diagnosis of dementia.

The univariate analyses were taken to compare the data of the death and survival groups, including demographic data, smoking, drinking, comorbidities, stroke severity and characteristics. Categorical variables were compared using the Pearson Chi-square test, and quantitative variables were compared using an independent samples t-test or the Mann-Whitney U test in appreciation.

The cumulative proportion of patients surviving in the groups with and without dementia was determined using the Kaplan-Meier survival analyses (26). In the multivariate analysis, we studied the association between dementia and risk of death using the Cox proportional hazards regression analysis with a backward procedure and with $\mathrm{p}>0.05$ as the criterion for exclusion to estimate hazard ratios (HRs), with $95 \%$ confidence intervals (CIs). These analyses were performed using SPSS for Windows, version 10.0 (SPSS Inc., Chicago, IL, USA).

\section{Results}

Follow-up, prevalence and incidence of dementia and mortality. Of the 619 patients, 39 (6.3\%) were diagnosed with dementia during admission and 107 (17.3\%) three months after index stroke. Thus, 146 (23.6\%) patients were diagnosed with dementia.

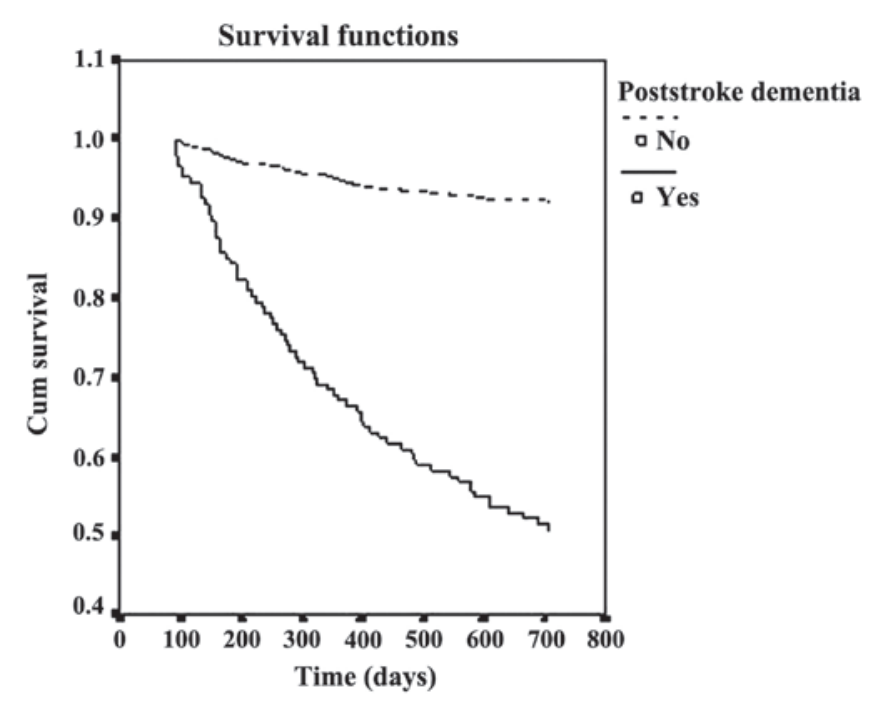

Figure 1. Relationship between probability of survival and time.

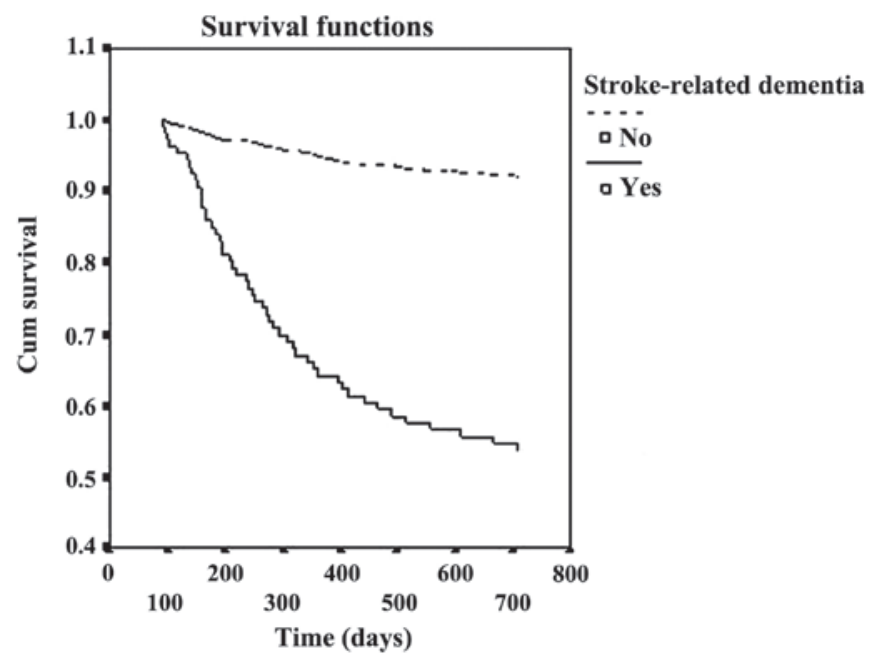

Figure 2. Relationship between probability of survival and time.

After a median follow-up of $10.3 \pm 5.7$ months, 112 patients (16.5\%) succumbed during the study. A total of 29 patients (4.7\%) were lost during follow-up. The median follow-up time was $9.1 \pm 5.3$ months and four of 29 patients were diagnosed as having dementia.

After a median follow-up of $21.2 \pm 5.6$ months, the cumulative proportion of case survival was 49.3 and $92.5 \%$ in patients with and without dementia, respectively. The survival curves were significantly different $(\mathrm{p}<0.001)$ between the two groups (Figs. 1 and 2).

Demographic characteristics, smoking, drinking, comorbidities, dementia and stroke features of patients according to death. Table I indicates the demographic characteristics, smoking and drinking status, and comorbidities of deceased and surviving patients. Deceased patients were older (74.6 \pm 11.2 vs. $65.2 \pm 9.3, \mathrm{p}<0.001)$, less frequent with diabetes mellitus [odds ratio (OR), 0.93; 95\% CI, 0.63-1.40], and more frequent in female (OR, 1.04; 95\% CI, 0.72-1.48), hypertension (OR, 1.13; 95\% CI, 0.75-1.70), myocardial infarction (OR, 1.26; 95\% CI, 0.67-2.39), heart failure (OR, 1.22; 95\% CI, 0.61-2.43), 
Table I. Demographic characteristics, smoking, drinking and comorbidities according to death after stroke.

\begin{tabular}{|c|c|c|c|}
\hline Variable & Death $(n=112)$ & Survival $(\mathrm{n}=507)$ & P-value or OR $(95 \% \mathrm{CI})^{\mathrm{a}}$ \\
\hline Age (years), mean \pm SD & $74.6 \pm 11.2$ & $65.2 \pm 9.3$ & $\mathrm{p}<0.001$ \\
\hline Lower education $(\leq 6 \mathrm{y}), \mathrm{n}(\%)$ & $38(33.9)$ & $187(36.9)$ & $0.881(0.543-1.429)$ \\
\hline Female, n $(\%)$ & $57(50.9)$ & $249(49.1)$ & $1.04(0.72-1.48)$ \\
\hline Hypertension, n (\%) & $63(56.3)$ & $271(53.5)$ & $1.13(0.75-1.70)$ \\
\hline Diabetes mellitus, n (\%) & $34(30.3)$ & $158(31.1)$ & $0.93(0.63-1.40)$ \\
\hline Myocardial infarction & $12(10.7)$ & $43(8.5)$ & $1.26(0.67-2.39)$ \\
\hline Heart failure, n (\%) & $15(13.4)$ & $59(11.6)$ & $1.22(0.61-2.43)$ \\
\hline Atrial fibrillation, n (\%) & $39(34.8)$ & $97(19.1)$ & $2.24(1.41-3.53)$ \\
\hline Prior stroke, n (\%) & $28(25.0)$ & $65(12.8)$ & $2.28(1.40-3.70)$ \\
\hline Current smoking, n (\%) & $47(41.9)$ & $192(37.1)$ & $1.16(0.76-1.79)$ \\
\hline Daily alcohol intake, n (\%) & $39(34.8)$ & $149(28.8)$ & $1.36(0.83-2.21)$ \\
\hline Post-stroke dementia, n (\%) & $74(66.1)$ & $72(14.2)$ & $12.01(7.35-19.64)$ \\
\hline
\end{tabular}

${ }^{\mathrm{a}} \mathrm{OR}$ was adjusted for age, educational level and gender. OR, odds ratio; CI, confidence interval; SD, standard deviation.

Table II. Stroke features according to death after stroke.

\begin{tabular}{|c|c|c|c|}
\hline Variable & $\begin{array}{l}\text { Death }) \\
(\mathrm{n}=112\end{array}$ & $\begin{array}{l}\text { Survival } \\
(\mathrm{n}=507)\end{array}$ & $\begin{array}{c}\text { P-value or } \\
\text { OR }(95 \% \text { CI) }\end{array}$ \\
\hline \multicolumn{4}{|l|}{ Location, n (\%) } \\
\hline Left hemisphere & $47(41.9)$ & $206(40.1)$ & $1.48(0.95-2.28)^{\mathrm{a}}$ \\
\hline Right hemisphere & $49(43.8)$ & 145 (28.6) & \\
\hline Vertebrobasilar & $16(14.3)$ & $156(30.8)$ & \\
\hline Type of lesion, n (\%) & & & $2.15(1.49-3.11)^{\mathrm{b}}$ \\
\hline Single & $66(58.9)$ & $386(76.9)$ & \\
\hline Multiple & $46(41.1)$ & $116(23.1)$ & \\
\hline $\begin{array}{l}\text { Stroke } \\
\text { mechanism, n (\%) }\end{array}$ & & & $4.21(2.36-7.53)^{\mathrm{c}}$ \\
\hline Thrombotic & $86(76.8)$ & $461(90.9)$ & \\
\hline Embolic & $23(20.5)$ & $30(5.9)$ & \\
\hline Others & $3(2.7)$ & $16(3.2)$ & \\
\hline $\begin{array}{l}\text { NIH stroke } \\
\text { scale (SD) }\end{array}$ & $9.34(6.7)$ & $6.81(4.7)$ & $\mathrm{p}<0.001$ \\
\hline \multicolumn{4}{|c|}{$\begin{array}{l}\text { OR was adjusted for age, educational level and gender. }{ }^{\text {aRight }} \\
\text { vs. left; }{ }^{\text {b }} \text { multiple vs. single; 'embolic vs. thrombotic; OR, odds ratio; } \\
\text { CI, confidence interval. }\end{array}$} \\
\hline
\end{tabular}

atrial fibrillation (OR, 2.24; 95\% CI, 1.41-3.53), prior stroke (OR, 2.28, 95\% CI, 1.40-3.70), current smoking (OR, 1.16; 95\% CI, 0.76-1.79), daily alcohol intake (OR, 1.36; 95\% CI, 0.83-2.21), and dementia (OR, 12.01; 95\% CI, 7.35-19.64). Only differences in age $(\mathrm{p}<0.001)$, atrial fibrillation $(\mathrm{p}<0.001)$, prior stroke $(\mathrm{p}=0.001)$ and dementia $(\mathrm{p}<0.001)$ reached statistical significance.

Table II shows the stroke features according to death. Stroke features associated with death included multiple stroke lesions (OR, 2.15; 95\% CI, 1.49-3.11), and embolism (OR, 4.21; $95 \%$ CI, 2.36-7.53), and NIH stroke scale score $(\mathrm{p}<0.001)$.

Multivariate analysis of death after ischemic stroke in patients with dementia. Independent predictors for death in patients
Table III. Cox proportional hazards regression analysis according to dementia.

\begin{tabular}{lc}
\hline Variable & SE OR (95\% CI) \\
\hline Age (years) & $1.06(1.02-1.10)$ \\
Atrial fibrillation & $1.78(1.32-2.40)$ \\
Previous stroke & $2.14(1.49-3.08)$ \\
NIH stroke scale & $1.15(1.04-1.27)$ \\
Dementia & $7.21(3.85-13.49)$
\end{tabular}

Values are expressed as HR (95\% CI). HR, hazard ratio; CI, confidence interval.

with ischemic stroke were age (HR, 1.06; 95\% CI, 1.02-1.10), atrial fibrillation ( $\mathrm{HR}, 1.78 ; 95 \% \mathrm{CI}, 1.32-2.40$ ), previous stroke (HR, 2.14; 95\% CI, 1.49-3.08), NIH stroke scale score (HR, 1.95; 95\% CI, 1.04-1.27), and dementia (HR, 7.21; 95\% CI, 3.85-13.49) in the Cox's regression model (Table III).

\section{Discussion}

Chongqing, the largest city in southwest China, has an urban population of five million individuals, of whom $93.6 \%$ are Han, and have similar lifestyles (27). Furthermore, the social and economic characteristics of the city is a miniature version of China today, and can be a good sample to study disease features. In the present study, the Kaplan-Meier analysis revealed that the cumulative proportion of survival cases was 49.3 and $92.5 \%$ in patients with and without dementia, after median follow-up of $21.2 \pm 5.6$ months. The mortality rate of patients with dementia was $>4$-fold that of patients without dementia.

The results of the present study with regard to the cumulative proportion of survival of dementia after stroke str consistent with other studies in western countries. Previous findings on vascular dementia suggested that patients with vascular dementia had a higher risk for 
mortality compared to the control subjects $(28,29)$. A study in Finland showed dementia is a significant predictor of poor long-term survival and death from brain-associated causes in patients with acute stroke (30). Barba et al (31) also found that dementia increased the risk for mortality in stroke patients. A study demonstrated that the mortality rate was 15.90 deaths/100 person-years in dementia patients with ischemic stroke and 5.37 deaths/100 person-years in non-dementia patients with ischemic stroke during a period of up to 10 years of follow-up (32). Another study suggested that the cumulative proportion surviving after a median follow-up of 58.6 months was $38.9 \pm 0.08 \%$ for those with dementia and $74.5 \pm 0.04 \%$ for those without dementia (12). There are discrepancies between our findings and those of the abovementioned studies. The reason may be because the duration gap and outpatient treatment is different.

Consistent with other studies (9,23-38), age, atrial fibrillation, NIH stroke scale, and prior stroke were found to be associated with death after stroke in the present study. We also found that dementia was associated with long-term survival of stroke patients. This association was independent of other predictors of post-stroke death such as older age, higher stroke severity, presence of atrial fibrillation and previous stroke. In a prospective study on the association between mortality and dementia after stroke, dementia was demonstrated to adversely influence long-term survival after stroke, even after adjusting for other commonly accepted predictors of stroke mortality (12). In studies of cognitive decline and death after first-ever stroke, dementia was also proven to be an important predictor $(9,39)$. Dementia was considered to have prognostic implications in stroke patients, i.e., stroke prior to the index stroke and dementia developed after stroke may determine a significant reduction in survival and were among the most important risk factors of mortality in these patients (31). Dementia was identified to be a significant independent risk factor for reduced survival after ischemic stroke, after adjusting for other recognized predictors of mortality in a 10-year follow-up study (32).

Four explanations may be proposed for the mechanism of the elevated risk of death among patients with dementia after ischemic stroke $(6,10,12,32,40,41)$. First, patients with dementia after stroke have an increased burden of cerebrovascular disease, which later may in return increase their risk of death. Second, patients with dementia tend to be treated less aggressively for stroke prophylaxis as well as other medical conditions for their weakened social abilities. Third, patients with dementia may be less compliant with prescribed treatment regiments. Fourth, dementia, either degenerative or vascular, tends to appear in an already weak individual and constitutes by itself a general deleterious condition.

In conclusion, mortality is increased in Chinese stroke patients with dementia. Dementia is a risk factor for death after stroke, independent of other factors including age, stroke severity, atrial fibrillation and previous stroke. Prevention and management of the dementia after stroke is critical to reduce the mortality after stroke.

\section{Acknowledgements}

The present study was funded by contract no. 2001-54-23 from the Science and Technology Committee of Chongqing, China.

\section{References}

1. Liu M, Wu B, Wang WZ, Lee LM, Zhang SH and Kong LZ: Stroke in China: Epidemiology, prevention, and management strategies. Lancet Neurol 6: 456-464, 2007.

2. Bonita R, Ford MA and Stewart AW: Predicting survival after stroke: a three-year follow-up. Stroke 19: 669-673, 1988.

3. Hollander M, Koudstaal PJ, Bots ML, Grobbee DE, Hofman A and Breteler MM: Incidence, risk, and case fatality of first ever stroke in the elderly population. The Rotterdam Study. J Neurol Neurosurg Psychiatry 74: 317-321, 2003.

4. Barker-Collo SL, Feigin VL, Lawes CM, Parag V, Senior H and Rodgers A: Reducing attention deficits after stroke using attention process training: a randomized controlled trial. Stroke 40: 3293-3298, 2009.

5. Arac A, Blanchard V, Lee M and Steinberg GK: Assessment of outcome following decompressive craniectomy for malignant middle cerebral artery infarction in patients older than 60 years of age. Neurosurg Focus 26: E3, 2009.

6. Barba R, Martínez-Espinosa S, Rodríguez-García E, Pondal M, Vivancos J and Del Ser T: Poststroke dementia : clinical features and risk factors. Stroke 31: 1494-1501, 2000.

7. Melkas S, Oksala NK, Jokinen H, Pohjasvaara T, Vataja R, Oksala A, Kaste M, Karhunen PJ and Erkinjuntti T: Poststroke dementia predicts poor survival in long-term follow-up: influence of prestroke cognitive decline and previous stroke. J Neurol Neurosurg Psychiatry 80: 865-870, 2009.

8. Shipley BA, Der G, Taylor MD and Deary IJ: Association between mortality and cognitive change over 7 years in a large representative sample of UK residents. Psychosom Med 69: 640-650, 2007.

9. Appelros P, Nydevik I and Viitanen M: Poor outcome after first-ever stroke: predictors for death, dependency, and recurrent stroke within the first year. Stroke 34: 122-126, 2003.

10. Moroney JT, Bagiella E, Tatemichi TK, Paik MC, Stern Y and Desmond DW: Dementia after stroke increases the risk of long-term stroke recurrence. Neurology 48: 1317-1325, 1997.

11. Rockwood K, Wentzel C, Hachinski V, Hogan DB, MacKnight C and McDowell I; Vascular Cognitive Impairment Investigators of the Canadian Study of Health and Aging: Prevalence and outcomes of vascular cognitive impairment. Neurology 54: 447-451, 2000.

12. Tatemichi TK, Paik M, Bagiella E, Desmond DW, Pirro M and Hanzawa LK: Dementia after stroke is a predictor of long-term survival. Stroke 25: 1915-1919, 1994.

13. Chen X, Zhou L, Zhang Y, Yi D, Liu L, Rao W, Wu Y, Ma D, Liu X, Zhou XH, Lin H, Cheng D and Yi D: Risk factors of stroke in Western and Asian countries: A systematic review and meta-analysis of prospective cohort studies. BMC Public Health 14: 776, 2014

14. Fuh JL, Teng EL, Lin KN, Larson EB, Wang SJ, Liu CY, Chou P, Kuo BI and Liu HC: The Informant Questionnaire on Cognitive Decline in the Elderly (IQCODE) as a screening tool for dementia for a predominantly illiterate Chinese population. Neurology 45: 92-96, 1995.

15. Chen P, Yu ES, Zhang M, Liu WT, Hill R and Katzman R: ADL dependence and medical conditions in Chinese older persons: a population-based survey in Shanghai, China. J Am Geriatr Soc 43: 378-383, 1995.

16. Zhou H, Deng J, Li J, Wang Y, Zhang M and He H: Study of the relationship between cigarette smoking, alcohol drinking and cognitive impairment among elderly people in China. Age Ageing 32: 205-210, 2003.

17. Zhou DH, Wang JY, Li J, Deng J, Gao C and Chen M: Study on frequency and predictors of dementia after ischemic stroke: the Chongqing stroke study. J Neurol 251: 421-427, 2004.

18. Katzman R, Zhang MY, Ouang-Ya-Qu, Wang ZY, Liu WT, Yu E, Wong SC, Salmon DP and Grant I: A Chinese version of the Mini-Mental State Examination; impact of illiteracy in a Shanghai dementia survey. J Clin Epidemiol 41: 971-978, 1988.

19. Katz S, Downs TD, Cash HR and Grotz RC: Progress in development of the index of ADL. Gerontologist 10: 20-30, 1970.

20. Lawton MP and Brody EM: Assessment of older people: self-maintaining and instrumental activities of daily living. Gerontologist 9: 179-186, 1969.

21. Pfeiffer E: A short portable mental status questionnaire for the assessment of organic brain deficit in elderly patients. J Am Geriatr Soc 23: 433-441, 1975.

22. Fuld PA: The Fuld Object-Memory Evaluation. Stoelting Instrument Co., Chicago, IL, 1981. 
23. Zhang M: Prevalence study on dementia and Alzheimer disease Zhonghua Yi Xue Za Zhi 70: 424-428, 30, 1990 (In Chinese).

24. Zhou B, Hong Z and Huang M: Prevalence of dementia in Shanghai urban and rural area. Zhonghua Liu Xing Bing Xue Za Zhi 22: 368-371, 2001 (In Chinese).

25. American Psychiatric Association: Diagnostic and Statistical Manual of Mental Disorders. 4th edition. American Psychiatric Association, Washington, DC, 1994.

26. Dinse GE and Lagakos SW: Nonparametric estimation of lifetime and disease onset distributions from incomplete observations. Biometrics 38: 921-932, 1982.

27. Gao BW, Wang W and Zou DC: Effects of change in urban-rural statistical definition in two censuses on urbanization process of Chongqing. Popul Res 26: 10-14, 2002 (In Chinese).

28. Koedam EL, Pijnenburg YA, Deeg DJ, Baak MM, van der Vlies AE, Scheltens P and van der Flier WM: Early-onset dementia is associated with higher mortality. Dement Geriatr Cogn Disord 26: 147-152, 2008.

29. Knopman DS, Rocca WA, Cha RH, Edland SD and Kokmen E: Survival study of vascular dementia in Rochester, MN. Arch Neurol 60: 85-90, 2003.

30. Melkas S, Laurila JV, Vataja R, Oksala N, Jokinen H, Pohjasvaara T, Leppavuori A, Kaste M, Karhunen PJ and Erkinjuntti T: Post-stroke delirium in relation to dementia and long-term mortality. Int J Geriatr Psychiatry 27: 401-408, 2012.

31. Barba R, Morin MD, Cemillán C, Delgado C, Domingo J and Del Ser T: Previous and incident dementia as risk factors for mortality in stroke patients. Stroke 33: 1993-1998, 2002.

32. Desmond DW, Moroney JT, Sano M and Stern Y: Mortality in patients with dementia after ischemic stroke. Neurology 59 537-543, 2002.
33. Kimura K, Minematsu K and Yamaguchi T; Japan Multicenter Stroke Investigators' Collaboration (J-MUSIC): Atrial fibrillation as a predictive factor for severe stroke and early death in 15,831 patients with acute ischaemic stroke. J Neurol Neurosurg Psychiatry 76: 679-683, 2005.

34. Vemmos KN, Bots ML, Tsibouris PK, Zis VP, Takis CE, Grobbee DE and Stamatelopoulos S: Prognosis of stroke in the south of Greece: 1 year mortality, functional outcome and its determinants: the Arcadia Stroke Registry. J Neurol Neurosurg Psychiatry 69: 595-600, 2000.

35. Vohra EA, Ahmed WU and Ali M: Aetiology and prognostic factors of patients admitted for stroke. J Pak Med Assoc 50: 234-236, 2000.

36. Rabkin SW, Mathewson FA and Tate RB: The relation of blood pressure to stroke prognosis. Ann Intern Med 89: 15-20, 1978.

37. Woo J, Kay R, Yuen YK and Nicholls MG: Factors influencing long-term survival and disability among three-month stroke survivors. Neuroepidemiology 11: 143-150, 1992.

38. Baptista MV, van Melle G and Bogousslavsky J: Prediction of in-hospital mortality after first-ever stroke: the Lausanne Stroke Registry. J Neurol Sci 166: 107-114, 1999.

39. Srikanth VK, Quinn SJ, Donnan GA, Saling MM and Thrift AG: Long-term cognitive transitions, rates of cognitive change, and predictors of incident dementia in a population-based first-ever stroke cohort. Stroke 37: 2479-2483, 2006.

40. Hoffmann M, Schmitt F and Bromley E: Comprehensive cognitive neurological assessment in stroke. Acta Neurol Scand 119: 162-171, 2009.

41. Ukraintseva S, Sloan F, Arbeev K and Yashin A: Increasing rates of dementia at time of declining mortality from stroke. Stroke 37: $1155-1159,2006$ 